\title{
Dominance of Haemophilus influenzae in ear discharge from Indigenous Australian children with acute otitis media with tympanic membrane perforation
}

Heidi C Smith-Vaughan ${ }^{1 *}$, Michael J Binks', Robyn L Marsh', Mirjam Kaestli', Linda Ward ${ }^{1}$, Kim M Hare', Susan J Pizzutto ${ }^{1}$, Ruth B Thornton ${ }^{2}$, Peter S Morris ${ }^{1}$ and Amanda J Leach ${ }^{1}$

\begin{abstract}
Background: Indigenous Australian children living in remote communities experience high rates of acute otitis media with tympanic membrane perforation (AOMwiP). Otitis media in this population is associated with dense nasopharyngeal colonization of three primary otopathogens; Haemophilus influenzae, Streptococcus pneumoniae and Moraxella catarrhalis. Little is known about the relative abundance of these pathogens during infection. The objective of this study was to estimate the abundance and concordance of otopathogens in ear discharge and paired nasopharyngeal swabs from children with AOMwiP (discharge of not more than 6 weeks' duration and perforation size $<2 \%$ ).

Methods: Culture and quantitative PCR (qPCR) estimation of H. influenzae, S. pneumoniae, M. catarrhalis and total bacterial load were performed on paired nasopharyngeal and ear discharge swabs from 55 Indigenous children with AOMwiP aged 3.5 - 45.6 months and resident in remote communities.

Results: By culture, H. influenzae, S. pneumoniae, and M. catarrhalis were detected in $80 \%, 84 \%$ and $91 \%$ of nasopharyngeal swabs, and $49 \%, 33 \%$ and $4 \%$ of ear discharge swabs, respectively. Using qPCR, H. influenzae, S. pneumoniae, and M. catarrhalis were detected in $82 \%, 82 \%$, and $93 \%$ of nasopharyngeal swabs, and $89 \%, 41 \%$ and $18 \%$ of ear discharge swabs, respectively. Relative abundance of $H$. influenzae in ear discharge swabs was 0-68\% of the total bacterial load (median 2.8\%); whereas S. pneumoniae and M. catarrhalis relative abundances were consistently $<2 \%$ of the total bacterial load. S. pneumoniae and M. catarrhalis abundances were significantly lower in ear discharge compared with nasopharyngeal swabs $(p=0.001, p<0.001)$; no significant difference was observed in H. influenzae mean abundance at the two sites.

Conclusions: $\mathrm{H}$. influenzae was the dominant otopathogen detected in ear discharge swabs collected from children with AOMwiP. High prevalence and abundance of S. pneumoniae and M. catarrhalis in the nasopharynx did not predict ear discharge prevalence and abundances of these pathogens. PCR was substantially more sensitive than culture for ear discharge, and a necessary adjunct to standard microbiology. Quantitative methods are required to understand species abundance in polymicrobial infections and may be needed to measure accurately the microbiological impact of interventions and to provide a better understanding of clinical failure in these children.
\end{abstract}

Keywords: Otitis media, Haemophilus influenzae, Moraxella catarrhalis, Streptococcus pneumoniae, Bacterial load, Abundance, Relative abundance, qPCR

\footnotetext{
* Correspondence: heidi@menzies.edu.au

'Menzies School of Health Research, Charles Darwin University, Darwin,

Northern Territory, Australia

Full list of author information is available at the end of the article
} 


\section{Background}

Indigenous children in remote communities of Australia's Northern Territory (NT) experience frequent episodes of acute otitis media (AOM) [1]. Bulging of the tympanic membrane caused by suppuration in the middle ear will often lead to spontaneous perforation in this population. A 2001 survey of 709 Indigenous children aged 6 to 30 months reported a $24 \%$ prevalence of tympanic membrane perforation (TMP); 7\% AOM with perforation (AOMwiP), 2\% dry perforation, and 15\% chronic suppurative otitis media (CSOM) [2]. Surveys conducted after introduction of pneumococcal conjugate vaccine in the NT have shown $<10 \%$ of Indigenous children have bilateral normal healthy ears and approximately $20 \%$ of children have TMP (unpublished). Randomised controlled trials confirm that otitis media in this population is difficult to cure $[1,3,4]$. A better understanding of otitis media pathogenesis is needed to guide improved prevention and treatment strategies, particularly in highrisk populations.

Internationally, a compilation of eight studies involving tympanocentesis and culture of middle ear fluid in AOM without perforation reported Streptococcus pneumoniae, followed by nontypeable Haemophilus influenzae (NTHi), and Moraxella catarrhalis as the most commonly cultured bacteria [5]. In studies of the bacteriology of spontaneous otorrhea associated with AOM, H. influenzae, S. pneumoniae, and Streptococcus pyogenes were primarily identified by culture [6-8]. Tympanocentesis has not been ethically approved for research purposes in the NT, thus only the bacteriology of spontaneous otorrhea associated with AOMwiP and CSOM have been described in NT Indigenous children. Our previous culture-based studies of AOMwiP found NTHi in 55 to $60 \%$, S. pneumoniae in 30 to $40 \%$, and $M$. catarrhalis in less than $10 \%$ of ear discharge swabs [9]. In children with CSOM, secondary pathogens such as Pseudomonas aeruginosa and Staphylococcus aureus are more often involved, but NTHi remains a commonly cultured otopathogen [4].

It is unclear whether otitis media is dominated by a single species or whether an array of microbes contribute to disease severity and chronicity. Culture-based studies report co-infection with multiple otopathogens and culture-independent studies have demonstrated a complex polymicrobial middle ear bacteriology [10-12]. The aims of the current study were : i) to measure the prevalence and abundance of $H$. influenzae, S. pneumoniae and $M$. catarrhalis in ear discharge from children with AOMwiP to determine if a single species dominates; and ii) to determine if bacterial prevalence and abundance in nasopharyngeal swabs reflects that in the middle ear during AOMwiP.

\section{Methods}

\section{Ethical approval}

Ethical approval for this study was granted by the Human Research Ethics Committee of the Northern Territory Department of Health and Menzies School of Health Research (HREC07/85). The swabs were collected as part of several clinical studies with written consent from a parent/guardian using a consent process (consent form and information sheet) approved by the Human Research Ethics Committee.

\section{Ear examinations}

Ears were examined using video otoscopy and tympanometry. AOMwiP was defined as a perforation for less than 6 weeks' duration and a perforation size $<2 \%$ of the pars tensa [3]. Ear discharge swabs were collected following cleaning of debris from the external canal then by positioning swabs as close to the perforation as possible to collect fresh otorrhea at the perforation [13].

\section{Participants and sample collection}

This study analysed 55 paired nasopharyngeal and ear discharge swabs from 51 Indigenous children resident in remote communities of the Northern Territory of Australia. The children were 3.5 - 45.6 months of age. Each swab had been stored in $1.0 \mathrm{ml}$ skim milk-tryptoneglucose-glycerol-broth [14] at $-80^{\circ} \mathrm{C}$. Swabs were selected from three completed studies: a randomised controlled trial (RCT) of long-term amoxycillin (up to 6 months) versus placebo for treatment of OME in 3 remote Indigenous communities [15]; a longitudinal carriage study of infants receiving 7 -valent pneumococcal conjugate vaccine and 23-valent pneumococcal polysaccharide vaccine in three remote Indigenous communities [16]; and an RCT of azithromycin versus amoxicillin for AOM in 16 communities [1]. All the available paired nasopharyngeal and ear discharge swabs were selected provided that the child had not received antimicrobial therapy in the previous seven days, and the parent/guardian had provided consent for further research (where applicable). Where a child had bilateral perforations, the left ear discharge was selected.

\section{Microbiological analysis and quantitative PCR estimates}

$10 \mu \mathrm{l}$ of the original swab medium was cultured using methods optimized for recovery of NTHi, S. pneumoniae and $M$. catarrhalis. NTHi were identified from bacitracinvancomycin-clindamycin chocolate agar plates based on colonial morphology (greyish, semi-opaque, smooth, flat or convex, 1-3 mm in size), $\mathrm{X}$ and $\mathrm{V}$ growth factor dependence, and lack of reaction with capsular antisera using the Phadebact ${ }^{\ominus}$ Haemophilus coagglutination test. Where recovery of NTHi was compromised by swarming Proteus 
species, a filtration step was included [4]. S. pneumoniae were identified from colistin naladixic acid plates based on colonial morphology (flat, usually dimpled, 1-3 $\mathrm{mm}$ in size), $\alpha$-haemolysis, sensitivity to optochin, and the Phadebact $^{\oplus}$ Pneumococcus Test. $M$. catarrhalis were identified from chocolate agar plates based on colonial morphology (discrete, smooth, glistening, white-grey, 1-3 mm colonies), 'hockey puck' movement when pushed, oxidase production, and Gram stain.

DNA was extracted from $200 \mu \mathrm{l}$ of each swab as described previously [17]. H. influenzae, S. pneumoniae, $M$. catarrhalis, and total bacterial load (16S rRNA gene amplicon) were estimated by quantitative real-time PCR (qPCR) using methods and acceptance criteria described previously [13]. For $H$. influenzae, the hpd\#3 qPCR assay [18] which demonstrated superior discrimination of $H$. influenzae and $H$. haemolyticus [19], was used. Total bacterial load data are estimates which need to be interpreted cautiously due to the biases inherent to the method. Bacteria have varied copy numbers of ribosomal operons (S. pneumoniae has 4 copies, and $H$. influenzae contains 7 copies); our assay uses $S$. pneumoniae to create standard curves for quantification. The limit of detection for each qPCR assay was equivalent to $9 \times 10^{4}$ cells/swab for the total bacterial load assay; $1 \times 10^{4}$ cells/swab for the $H$. influenzae and $M$. catarrhalis assays; and $0.9 \times 10^{4}$ cells/swab for the S. pneumoniae assay. The limit of quantification was $1 \times 10^{5}$ cells/swab for the $H$. influenzae and $M$. catarrhalis qPCR assays, and $0.9 \times 10^{5}$ cells/swab for $S$. pneumoniae and total bacterial load assays. The limit of detection for culture (based on analysis of $10 \mu \mathrm{l}$ of $1 \mathrm{ml}$ swab) was $1 \times 10^{2}$ cells/swab.

\section{Statistical analysis}

The bacterial abundance dataset contained a large proportion of zero counts and was not normally distributed. Therefore the non-parametric Wilcoxon matched-pairs signed-ranks test was used to compare bacterial abundance estimates in the paired nasopharyngeal and ear discharge swabs for all data, and for swabs where the ear discharge was positive for the bacterium of interest. All statistical analyses were undertaken using STATA version 12.0 (StataCorp LP). Non-metric multi-dimensional scaling (NMDS) was performed using Primer-E Ltd (v 6.1.13, Plymouth UK) and was based on a Bray-Curtis similarity matrix of 4th root transformed abundance data. The location of each data point in low-dimensional space is based on qPCR estimates of $H$. influenzae, $S$. pneumoniae and M. catarrhalis; all swabs negative for the three species were excluded (five swabs). Each data point refers to an ear discharge swab and is coloured according to a dichotomous abundance measure $\left(>10^{5}\right.$ or $<10^{5}$ cells $\left./ \mathrm{ml}\right)$. A nominal cutoff of $10^{5}$ cells $/ \mathrm{ml}$ was selected to represent high versus low or no infection based on other studies $[17,20]$.

\section{Results}

\section{Detection of pathogens by culture and qPCR}

Among the 55 nasopharyngeal swabs, $H$. influenzae, $S$. pneumoniae and M. catarrhalis were detected in $80 \%$, $84 \%$, and $91 \%$ by culture and in $82 \%, 82 \%$ and $93 \%$ by qPCR. Among the 55 ear discharge swabs, $H$. influenzae, S. pneumoniae and M. catarrhalis were detected in 49\%, $33 \%$, and $3.6 \%$ by culture and in $89 \%, 41 \%$ and $18 \%$ by qPCR (Figure 1). By qPCR, all three species were detected in $73 \%$ (40) of nasopharyngeal swabs, and in

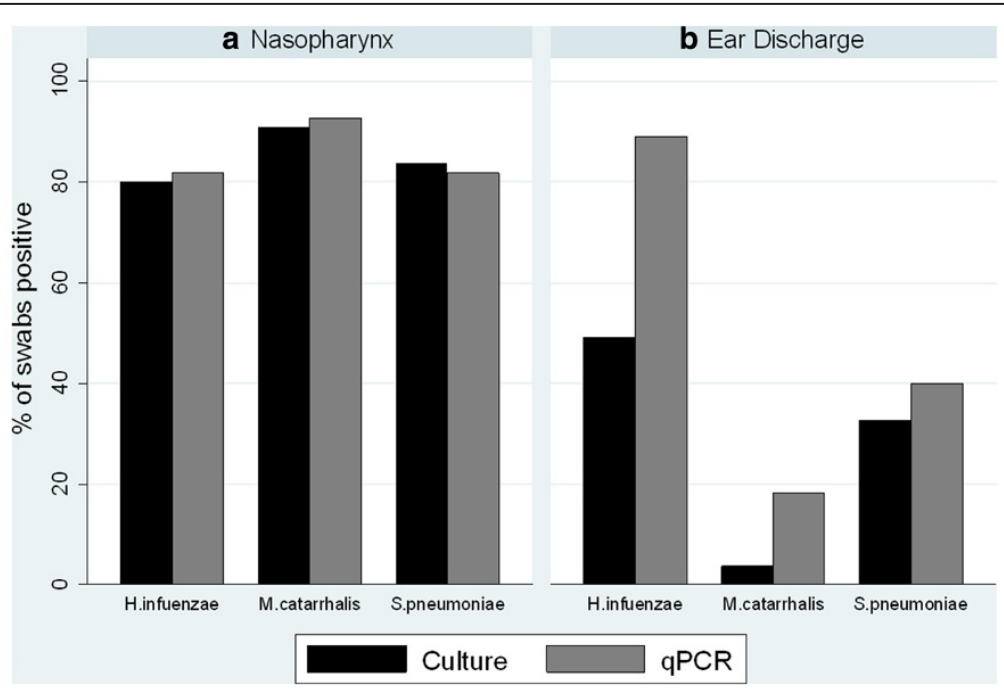

Figure 1 Culture and qPCR of nasopharyngeal and ear discharge swabs from 55 Indigenous Australian children with AOMwiP. Percentage of (a) nasopharyngeal swabs and (b) ear discharge swabs positive by culture and qPCR for $H$. influenzae, S. pneumoniae and M. catarrhalis. 
$5 \%$ (3) of ear discharge swabs; at least two species were detected in $87 \%$ (48) of nasopharyngeal swabs and $51 \%$ (28) of ear discharge swabs. The sensitivity of the qPCRs was over $80 \%$ compared to culture in all cases except for $M$. catarrhalis ear discharge where there were only 2 culture-positive swabs limiting the resolution of such a comparison. The specificities were less consistent due to the relatively small number of swabs that were not positive by both qPCR and culture; with $H$. influenzae the notable exception where $22 / 28(79 \%)$ of the culture-negative swabs were qPCR positive. Sensitivities and specificities are presented in Table 1.

Other potential otopathogens were cultured less frequently; for example, beta-haemolytic streptococci were detected in 5 (9\%) of ear discharge swabs by culture, and not in any nasopharyngeal swabs.

\section{qPCR estimation of bacterial abundance}

The geometric mean bacterial abundance estimates for individual species and for total bacterial load are shown in Figure 2. Highest nasopharyngeal geometric mean bacterial abundance was observed for $M$. catarrhalis $\left(7.3 \times 10^{5}\right.$ cells $/ \mathrm{ml}, 95 \%$ CI $\left.2.5 \times 10^{5}-2.1 \times 10^{6}\right)$, followed by H. influenzae $\left(8.5 \times 10^{4}\right.$ cells $/ \mathrm{ml}, 95 \%$ CI $\left.1.9 \times 10^{4}-3.7 \times 10^{5}\right)$ and S. pneumoniae $\left(5.2 \times 10^{4}\right.$ cells/ml, $95 \%$ CI $1.3 \times 10^{4}$ $\left.2.1 \times 10^{5}\right)$. In ear discharge swabs, $H$. influenzae demonstrated the highest geometric mean bacterial abundance $\left(3.6 \times 10^{5}\right.$ cells $/ \mathrm{ml}, 95 \%$ CI $\left.1 \times 10^{5}-1.3 \times 10^{6}\right)$, followed by $S$. pneumoniae $\left(1.6 \times 10^{2}\right.$ cells $/ \mathrm{ml}, 95 \%$ CI $\left.30-8.3 \times 10^{2}\right)$ and M. catarrhalis (9 cells $/ \mathrm{ml}, 95 \%$ CI 2.6-31). The large number of $M$. catarrhalis and $S$. pneumoniae negative ear discharge swabs contributed to their low geometric mean abundance. The geometric mean total bacterial loads estimated on a $16 \mathrm{~S}$ rRNA gene amplicon were $1.8 \times 10^{7}$ cells $/ \mathrm{ml}\left(95 \%\right.$ CI $\left.3 \times 10^{7}-6.8 \times 10^{7}\right)$ for nasopharyngeal swabs and $4.6 \times 10^{7}$ cells $/ \mathrm{ml}\left(95 \%\right.$ CI $3 \times 10^{7}$ $6.8 \times 10^{7}$ ) for ear discharge swabs.

Table 1 Number of swabs positive by qPCR and culture, sensitivity and specificity of qPCR compared with culture

\begin{tabular}{ccccccccc}
\hline & \multicolumn{2}{c}{ H. influenzae } & & \multicolumn{2}{c}{ S. pneumoniae } & & \multicolumn{2}{c}{ M. catarrhalis } \\
\cline { 2 - 3 } & NP & ED & & NP & ED & & NP & ED \\
\hline qPCR + Culture+ & 37 & 27 & & 42 & 16 & & 49 & 1 \\
qPCR + Culture- & 8 & 22 & 3 & 6 & & 9 \\
qPCR-Culture+ & 7 & 0 & 4 & 2 & & 1 \\
qPCR-Culture- & 3 & 6 & & 6 & 31 & & 3 & 44 \\
Sensitivity & 0.84 & 1 & & 0.91 & 0.89 & & 0.96 & 0.5 \\
Specificity & 0.27 & 0.21 & & 0.67 & 0.84 & & 0.9 & 0.83 \\
\hline
\end{tabular}

$\mathrm{NP}$, nasopharynx.

$E D$, ear discharge.
Comparison of bacterial abundance in nasopharyngeal and ear discharge swabs

In a comparison of all samples (Figure 2), total bacterial load was significantly higher in ear discharge compared with nasopharyngeal swabs $(\mathrm{p}=0.002)$. Abundance of $S$. pneumoniae $(\mathrm{p}=0.001)$ and $M$. catarrhalis $(\mathrm{p}<0.001)$ was significantly lower in ear discharge, and no significant difference was seen for $H$. influenzae between sites. While these data illustrate the average difference in abundance between these specimen types, the effect of the negative swabs may hide relationships that are dependent on presence of the pathogen. Thus, an analysis of the abundance of each species in qPCR-positive ear discharge swabs and their paired nasopharyngeal swabs was done (Figure 3 ). With negative qPCR swabs excluded, the geometric mean abundance in ear discharge compared to nasopharyngeal swabs was: significantly higher for $H$. influenzae ( $\mathrm{p}=0.040)$ and total bacterial load ( $\mathrm{p}=0.002)$; not different for S. pneumoniae; and significantly lower for $M$. catarrhalis $(\mathrm{P}=0.005$; based on only 10 qPCR positive ear discharge swabs).

\section{Relative abundance of each species as a proportion of the} total bacterial load

The relative abundances of individual species were estimated as a proportion of the total bacterial load. The median relative abundances of $H$. influenzae, S. pneumoniae and $M$. catarrhalis in nasopharyngeal swabs was $3.8 \%$ (range 0-48\%), 2\% (0-43\%) and 13\% (0-44\%), respectively. In contrast, the median relative abundance of $S$. pneumoniae (0\%; range, $0-12 \%$ ) and $M$. catarrhalis (0\%, range $0-1.8 \%)$ in ear discharge was low. The median $H$. influenzae abundance in ear discharge was marginally higher at $2.8 \%$, but with a range of up to $68 \%$ of the total bacterial load. Figure 4 illustrates the median proportions of $H$. influenzae, S. pneumoniae and M. catarrhalis in nasopharyngeal and ear discharge swabs demonstrating the dominance of $H$. influenzae in ear discharge. Notably, a large proportion of the total bacterial load represented bacteria that we did not identify, and which may have originated from the middle ear or the ear canal. Non-metric Multidimensional Scaling (NMDS) to visualize
the similarity of samples based on bacterial abundance in
individual ear discharge swabs
Conceptualisation of bacterial abundance data from individual swabs is complicated by data from the three variables (H. influenzae, S. pneumoniae, M. catarrhalis abundance), the large variance in bacterial abundance estimates, and the high frequency of negative results. In this case, we used non-metric multi-dimensional scaling (NMDS) as a tool for visualization of a similarity matrix of individual swabs based on the $H$. influenzae, $S$. pneumoniae and $M$. catarrhalis abundance data. The 


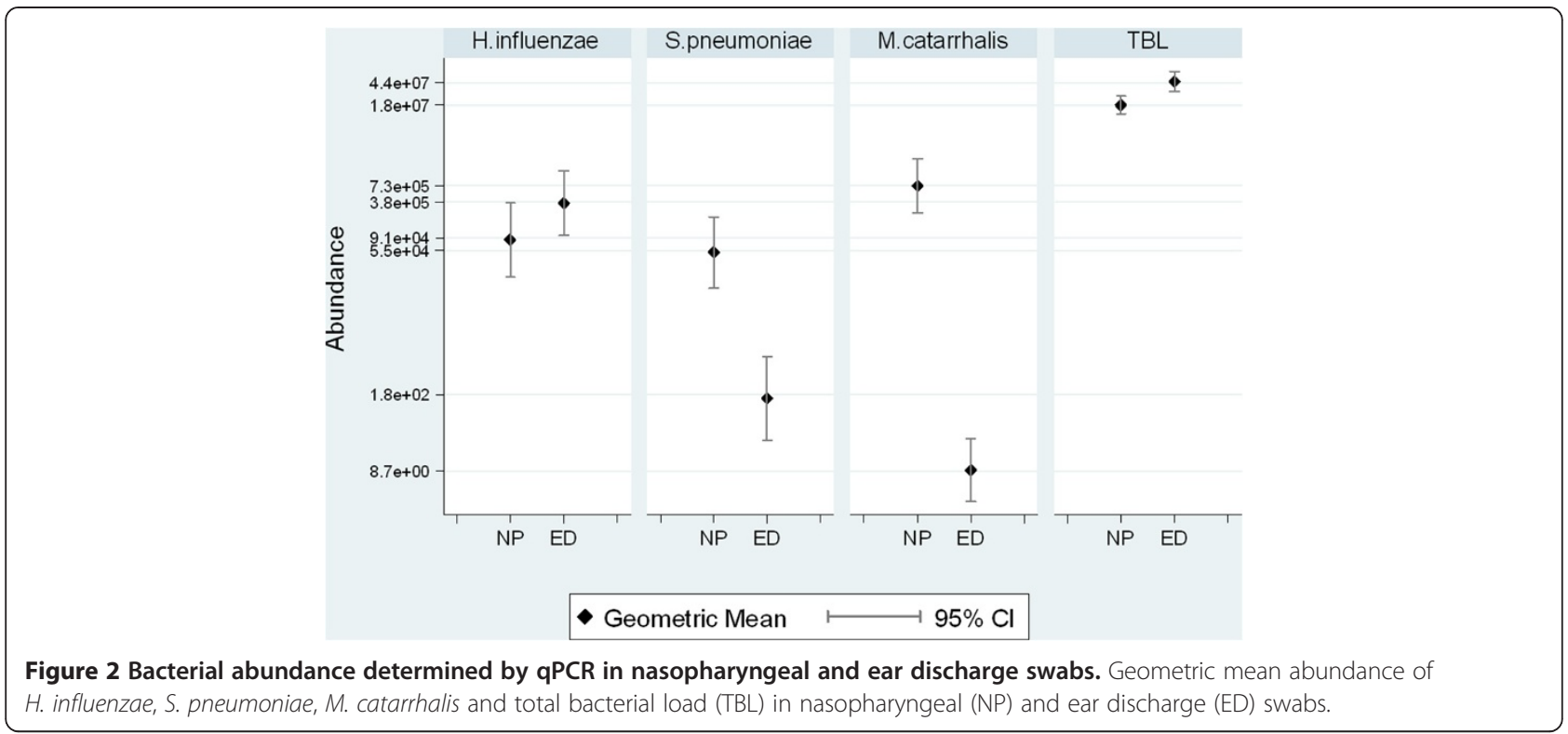

NMDS uses the similarity matrix to determine the location of each data point (indicative of each swab) in two-dimensional space with similar swabs "clustering" together. As shown in Figure 5a, the majority of ear discharge swabs contained $>10^{5} \mathrm{H}$. influenzae cells $/ \mathrm{ml}$. Figure $5 \mathrm{~b}$ and $5 \mathrm{c}$ show that ear discharge swabs with $>10^{5}$ S. pneumoniae cells $/ \mathrm{ml}$ or $>10^{5} \mathrm{M}$. catarrhalis cells $/ \mathrm{ml}$ coexist with $H$. influenzae counts of $>10^{5}$ cells $/ \mathrm{ml}$, with a single exception in which S. pneumoniae dominated the other species.

\section{Discussion}

In nasopharyngeal swabs collected from Indigenous children with AOMwiP, prevalence of $H$. influenzae, $S$. pneumoniae and $M$. catarrhalis by $\mathrm{qPCR}$ was high (82-93\%), with $87 \%$ of swabs positive for at least two pathogenic species. In paired ear discharge swabs, $H$. influenzae was not only a very commonly detected pathogen ( $89 \%$ of swabs by qPCR), it was more dominant, in terms of abundance, than S. pneumoniae and $M$. catarrhalis. S. pneumoniae was next most common and abundant in ear discharge, while $M$. catarrhalis (the dominant otopathogen in the nasopharynx) had low prevalence and abundance in ear discharge. At least two otopathogenic species were detected concurrently in $51 \%$ of ear discharge swabs; in addition, beta-haemolytic streptococci were detected in $9 \%$ of ear discharge swabs by culture, and may require further investigation in

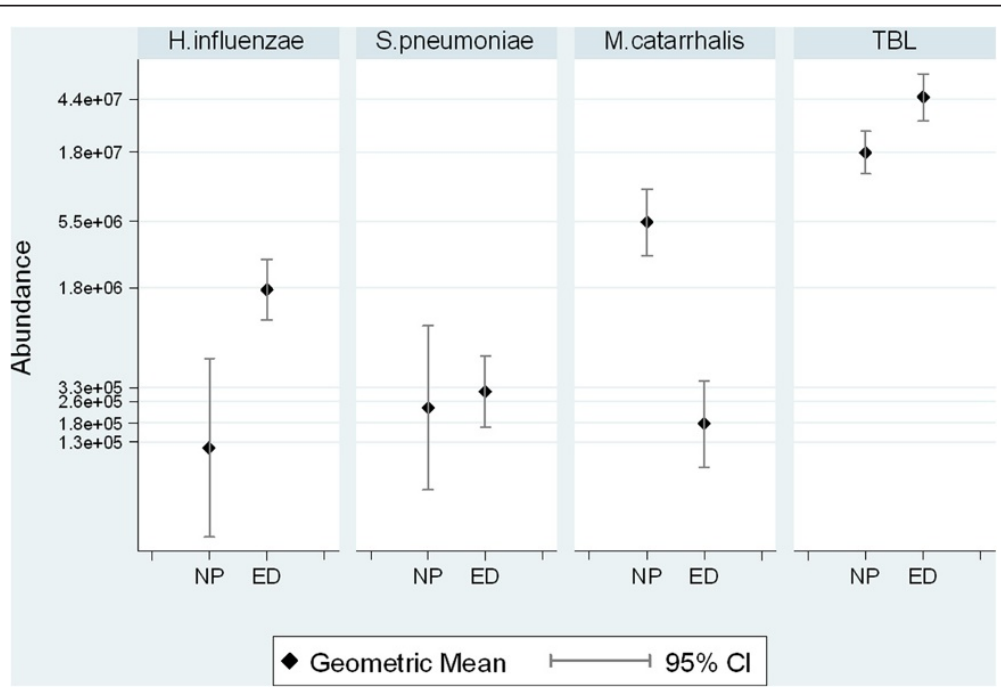

Figure 3 Bacterial abundance determined by qPCR in paired swabs where ear discharge was positive. Comparison of qPCR estimates where ear discharge (ED) swabs were positive for the pathogen of interest, and paired nasopharyngeal (NP) swabs. TBL, total bacterial load. 


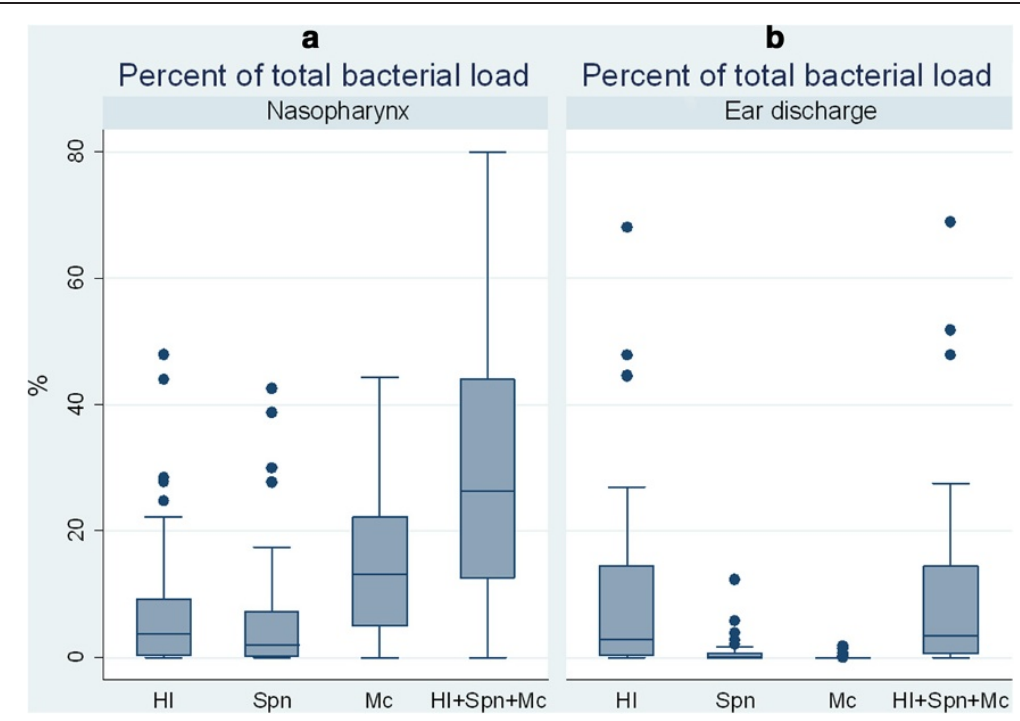

Figure 4 Relative abundance of $H$. influenzae, S. pneumoniae and $M$. catarrhalis in nasopharyngeal and ear discharge swabs. Median relative abundance and interquartile ranges for $\mathrm{H}$. influenzae, S. pneumoniae, $M$. catarrhalis and a combination of the three bacteria as a proportion of total bacterial load in nasopharyngeal (a) and ear discharge (b) swabs.

future studies. The contribution of various otopathogens to polymicrobial ear disease remains to be determined, and is likely to change during different stages of infection.

Estimation of the total bacterial load in swabs made possible the estimation of the relative abundance of the pathogens in each specimen. While $H$. influenzae, $S$. pneumoniae and $M$. catarrhalis generally represent a small proportion of the total bacterial load in ear discharge, $H$. influenzae could reach proportions of $68 \%$ and was clearly the dominant pathogen amongst these three otopathogens. Visualisation of the individual swabs using NMDS supported the primary statistical analysis that $H$. influenzae frequently exceeds abundance measures of $10^{5}$ cells $/ \mathrm{ml}$, and where ear discharge swabs contained S. pneumoniae or M. catarrhalis at abundance measures greater than $10^{5}$ cells $/ \mathrm{ml}$, this was always in the presence of high $H$. influenzae abundance $\left(>10^{5}\right.$ cells $/ \mathrm{ml}$ ) with one exception where $S$. pneumoniae dominated. Numerous studies have demonstrated the importance of $H$. influenzae, S. pneumoniae and M. catarrhalis in otitis media; however, the generally minor representation of these three species among the total bacterial load of most ear discharge swabs highlights the need for future investigations of AOMwiP bacteriology using complementary qPCR and microbiomic analyses.

H. influenzae is also a dominant pathogen in chronic lower respiratory disease in this population. Infection of the lower airways with NTHi (defined as $>10^{4}$ colony forming units per $\mathrm{ml}$ bronchoalveolar lavage fluid) was identified in $47 \%$ of Australian Indigenous children with non-cystic fibrosis bronchiectasis, compared with an
$18 \%$ prevalence of S. pneumoniae lower airway infection [21]. The involvement of NTHi in mucosal diseases likely reflects a balance between high carriage rates, its status as an opportunistic pathogen, its ability to persist in a polymicrobial environment, and the host immune response. In its planktonic form, NTHi is effectively killed by complement [22] and serum antibodies [22,23] and is not commonly associated with systemic disease. Infection of the respiratory mucosa is likely reliant on a complex interaction of pathogen and host mucosal factors with data from adults with chronic lower respiratory disease implicating the importance of cell mediated immunity [24].

The discrepancy between culture and molecular detection techniques in ear discharge swabs was marked and clearly demonstrates that PCR is a necessary adjunct to standard microbiology for this specimen type. Biofilm [25] and intracellular infection $[25,26]$ which are proposed mechanisms employed by NTHi to survive and persist in the hostile mucosal environment represent one explanation for the discrepancy. Other explanations for the qPCR-positive, culture-negative swabs may be related to non-viable cells, an altered metabolic state [27] of the bacteria in the middle ear, or other determinants as discussed in greater detail elsewhere [17]. The culture-positive, qPCR-negative swabs cultured $<10$ colonies and were below the limit of detection for qPCR (as detailed in Methods), with the exception of two swabs which may have experienced PCR inhibition. For the qPCR-positive, culture-negative swabs, the bacterial loads varied widely.

A limitation of this study was the likely variation in quantity of swab material collected at the two sites and 


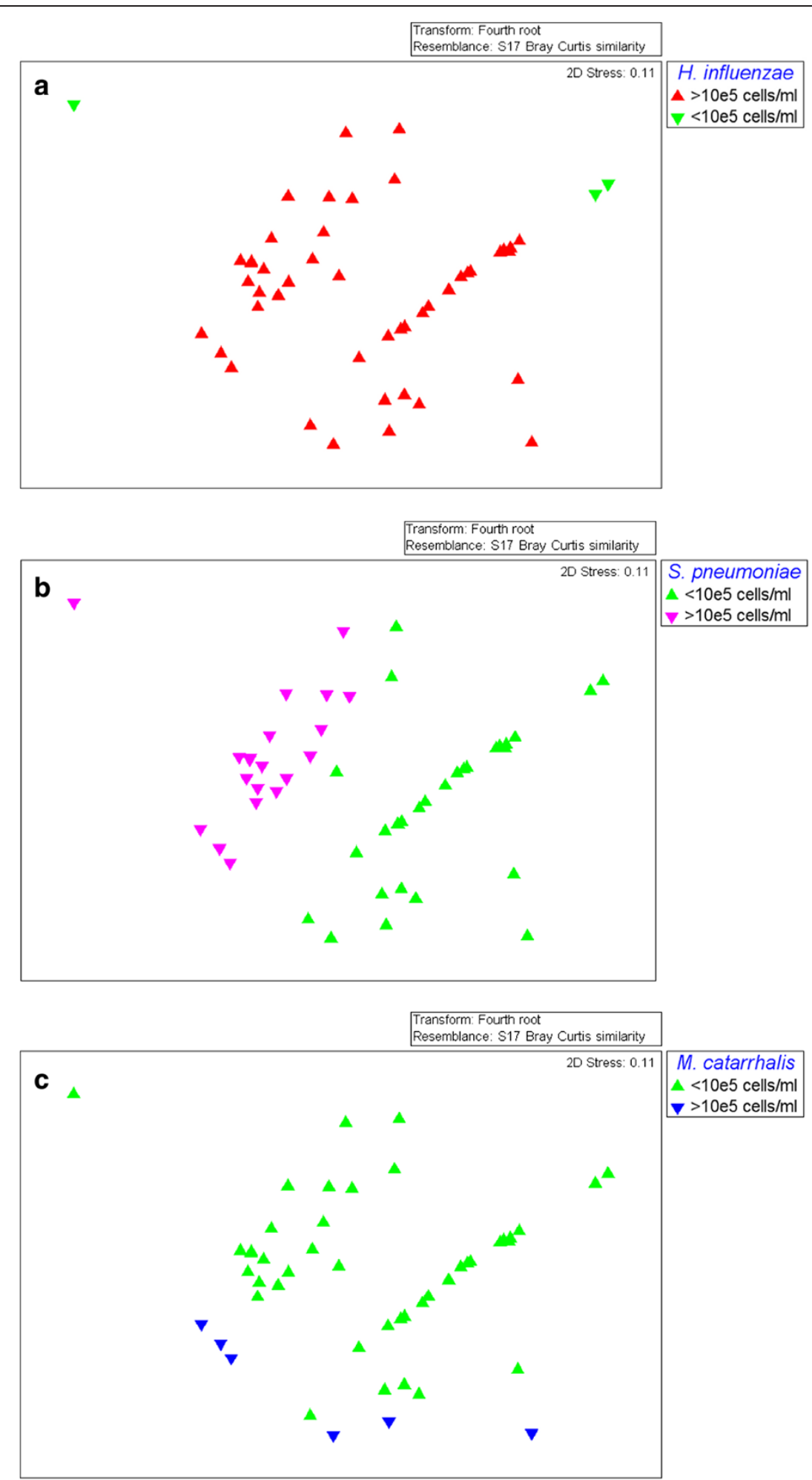

Figure 5 NMDS visualization of bacterial abundance determined by qPCR in ear discharge swabs. Non-Metric Multidimensional Scaling (NMDS) for visualization of the similarity of samples based on bacterial abundance in individual ear discharge swabs. Data points are coloured according to a dichotomous abundance measure of $>10^{5} \mathrm{cell} / \mathrm{s} / \mathrm{ml}$ or $<10^{5} \mathrm{cell} / \mathrm{s} / \mathrm{ml}$ for $\left.\mathbf{a}\right) \mathrm{H}$. influenzae; b) S. pneumoniae and c) $\mathrm{M}$. catarrhalis. a) Data points coloured according to $\mathrm{H}$. influenzae abundance; green $\left(<10^{5}\right.$ cells $\left./ \mathrm{ml}\right)$ or red $\left(>10^{5} \mathrm{cell} / \mathrm{s} / \mathrm{ml}\right)$. b) Data points coloured according to S. pneumoniae abundance; green $\left(<10^{5}\right.$ cells $\left./ \mathrm{ml}\right)$ or pink $\left(>10^{5}\right.$ cells $\left./ \mathrm{ml}\right)$. c) Data points coloured according to $M$. catarrhalis abundance; green $\left(<10^{5}\right.$ cells $\left./ \mathrm{ml}\right)$ or blue $\left(>10^{5}\right.$ cells $\left./ \mathrm{ml}\right)$. 
between individuals; however, our analysis of relative abundance, which provides a within sample measure, did not change the results. Collection of middle ear effusion from Indigenous Australian children by tympanocentesis for research purposes has not been ethically approved; thus our study relied on examination of otorrhea following spontaneous perforation. Despite our protocols to collect fresh otorrhea at the perforation following cleaning of the ear canal, these swabs may include canal flora (for example, $P$. aeruginosa), which may or may not be contributing to the infection. A further potential bias relates to the effect of the numerous other taxa present but unidentified in each swab, and originating from the middle ear or the ear canal, which may influence the abundance or possible interdependencies of the three main otopathogens. Finally, our study does not address the question of whether abundance of a pathogen in a swab is related to its contribution to infection; for the three otopathogens some support is provided by findings that nasopharyngeal load of these otopathogens was significantly associated with presence and severity of current ear disease $[17,28]$.

\section{Conclusions}

In conclusion, $H$. influenzae was the most prevalent and abundant pathogen identified in middle ear discharge from Indigenous children with AOMwiP. In the case of S. pneumoniae and M. catarrhalis, high prevalence and abundance in the nasopharynx did not predict ear discharge microbiology. qPCR was substantially more sensitive than culture for ear discharge, and a necessary adjunct to standard microbiology. Quantitative methods are required to measure species abundance and relative abundance in polymicrobial infections and better understand pathogenesis. Such methods may be needed to accurately measure the effectiveness of treatment and prevention interventions for complex polymicrobial infections such as otitis media and respiratory tract infections.

\section{Competing interests}

The authors declare that they have no competing interests.

\section{Authors' contributions}

HSV conceived the study, obtained funding and ethical approvals, and drafted the manuscript; MJB, RLM and KMH generated the data; MJB, MK and LW analysed the data; SJP, RLM, and RBT helped to draft the manuscript; PSM and AJL advised on intellectual content and provided critical manuscript review. All authors approved the final manuscript. All authors read and approved the final manuscript.

\section{Acknowledgments}

We would like to thank the families who participated in these studies and for their continued support of our research. We would also like to thank the Menzies Ear Health Research Team and Child Health Laboratory Team for clinical swabs, clinical data, and laboratory support. This project was funded by the Channel 7 Children's Research Foundation and the Australian National Health and Medical Research Council (1023781). HSV is supported by NHMRC Career Development Fellowship 1024175. AJL is supported by NHMRC
Elizabeth Blackburn Research Fellowship 1020561. RLM is supported by NHMRC Frank Fenner Early Career Fellowship 1034703. KMH is supported by NHMRC Gustav Nossal Postgraduate Scholarship 1038072. MJB and S.JP are supported by NHMRC Postgraduate Scholarships 1017225 and 1038415.

\section{Author details}

${ }^{1}$ Menzies School of Health Research, Charles Darwin University, Darwin,

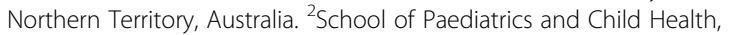
University of Western Australia, Perth, Western Australia, Australia.

Received: 3 June 2013 Accepted: 1 October 2013

Published: 8 October 2013

\section{References}

1. Morris PS, Gadil G, McCallum GB, Wilson CA, Smith-Vaughan HC, Torzillo P, et al: Single-dose azithromycin versus seven days of amoxycillin in the treatment of acute otitis media in Aboriginal children (AATAAC): a double blind, randomised controlled trial. Med J Aust 2010, 192:24-29.

2. Morris PS, Leach AJ, Silberberg P, Mellon G, Wilson C, Hamilton E, et al: Otitis media in young Aboriginal children from remote communities in Northern and Central Australia: a cross-sectional survey. BMC Pediatr 2005, 20:5-27.

3. Morris PS, Ballinger D, Leach AJ, Koops H, Hayhurst B, Stubbs E, et al: Recommendations for clinical care guidelines on the management of otitis media in Aboriginal and Torres Strait Islander populations. Indigenous EarlnfoNet 2001. http://www.healthinfonet.ecu.edu.au/otherhealth-conditions/ear.

4. Leach A, Wood Y, Gadil E, Stubbs E, Morris P: Topical ciprofloxin versus topical framycetin-gramicidin-dexamethasone in Australian aboriginal children with recently treated chronic suppurative otitis media: a randomized controlled trial. Pediatr Infect Dis J 2008, 27:692-698.

5. Murphy TF, Bakaletz LO, Smeesters PR: Microbial interactions in the respiratory tract. Pediatr Infect Dis J 2009, 28:S121-S126.

6. Grevers G, Wiedemann S, Bohn JC, Blasius RW, Harder T, Kroeniger W, et al: Identification and characterization of the bacterial etiology of clinically problematic acute otitis media after tympanocentesis or spontaneous otorrhea in German children. BMC Infect Dis 2012, 20:12-312.

7. Leibovitz E, Serebro M, Givon-Lavi N, Greenberg D, Broides A, Leiberman A, et al: Epidemiologic and microbiologic characteristics of culture-positive spontaneous otorrhea in children with acute otitis media. Pediatr Infect Dis J 2009, 28:381-384.

8. Marchisio P, Bianchini S, Baggi E, Fattizzo M, Galeone C, Torretta S, et al: A retrospective evaluation of microbiology of acute otitis media complicated by spontaneous otorrhea in children living in Milan, Italy. Infection 2013, 41:629-635.

9. Leach AJ, Morris PS: The burden and outcome of respiratory tract infection in Australian and aboriginal children. Pediatr Infect Dis J 2007, 26:S4-S7.

10. Liu CM, Cosetti MK, Aziz M, Buchhagen JL, Contente-Cuomo TL, Price LB, et al: The otologic microbiome: a study of the bacterial microbiota in a pediatric patient with chronic serous otitis media using 16SrRNA gene-based pyrosequencing. Arch Otolaryngol Head Neck Surg 2011, 137:664-668.

11. Pettigrew MM, Laufer AS, Gent JF, Kong Y, Fennie KP, Metlay JP: Upper respiratory tract microbial communities, acute otitis media pathogens, and antibiotic use in healthy and sick children. Appl Environ Microbiol 2012, 78:6262-6270.

12. Neumark T, Ekblom M, Brudin L, Groth A, Eliasson I, Molstad S, et al: Spontaneously draining acute otitis media in children: an observational study of clinical findings, microbiology and clinical course. Scand I Infect Dis 2011, 43:891-898.

13. Marsh RL, Binks MJ, Beissbarth J, Christensen P, Morris PS, Leach AJ, et al: Quantitative PCR of ear discharge from indigenous Australian children with acute otitis media with perforation supports a role for Alloiococcus otitidis as a secondary pathogen. BMC Ear Nose Throat Disord 2012, 12:11.

14. O'Brien KL, Nohynek H: Report from a WHO working group: standard method for detecting upper respiratory carriage of Streptococcus pneumoniae. Pediatr Infect Dis J 2003, 22:133-140.

15. Leach AJ, Morris PS, Mathews JD: Compared to placebo, long-term antibiotics resolve otitis media with effusion (OME) and prevent acute 
otitis media with perforation (AOMwiP) in a high-risk population: a randomized controlled trial. BMC Pediatr 2008, 8:23.

16. Mackenzie GA, Carapetis JR, Leach AJ, Morris PS: Pneumococcal vaccination and otitis media in Australian Aboriginal infants: comparison of two birth cohorts before and after introduction of vaccination. BMC Pediatr 2009, 9:14.

17. Smith-Vaughan H, Byun R, Nadkarni M, Jacques NA, Hunter N, Halpin S, et al: Measuring nasal bacterial load and its association with otitis media. BMC Ear Nose Throat Disord 2006, 6:10.

18. Wang X, Mair R, Hatcher C, Theodore MJ, Edmond K, Wu HM, et al: Detection of bacterial pathogens in Mongolia meningitis surveillance with a new real-time PCR assay to detect Haemophilus influenzae. Int J Med Microbiol 2011, 301:303-309.

19. Binks MJ, Temple B, Kirkham LA, Wiertsema SP, Dunne EM, Richmond PC, et al: Molecular surveillance of true nontypeable Haemophilus influenzae: an evaluation of PCR screening assays. PLoS One 2012, 7:e34083.

20. Abdeldaim GM, Stralin K, Korsgaard J, Blomberg J, Welinder-Olsson C, Herrmann B: Multiplex quantitative PCR for detection of lower respiratory tract infection and meningitis caused by Streptococcus pneumoniae, Haemophilus influenzae and Neisseria meningitidis. BMC Microbiol 2010, 10:310.

21. Hare KM, Grimwood K, Leach AJ, Smith-Vaughan H, Torzillo PJ, Morris PS, et al: Respiratory bacterial pathogens in the nasopharynx and lower airways of Australian indigenous children with bronchiectasis. J Pediatr 2010, 157:1001-1005.

22. King PT, Ngui J, Gunawardena D, Holmes PW, Farmer MW, Holdsworth SR: Systemic humoral immunity to non-typeable Haemophilus influenzae. Clin Exp Immunol 2008, 153:376-384.

23. Sethi S, Wrona C, Grant BJ, Murphy TF: Strain-specific immune response to Haemophilus influenzae in chronic obstructive pulmonary disease. Am J Respir Crit Care Med 2004, 169:448-453.

24. King PT, Hutchinson PE, Johnson PD, Holmes PW, Freezer NJ, Holdsworth SR: Adaptive immunity to nontypeable Haemophilus influenzae. Am J Respir Crit Care Med 2003, 167:587-592.

25. Thornton RB, Rigby PJ, Wiertsema SP, Filion P, Langlands J, Coates HL, et al: Multi-species bacterial biofilm and intracellular infection in otitis media. BMC Pediatr 2011, 11:94.

26. Coates $H$, Thornton $R$, Langlands J, Filion P, Keil AD, Vijayasekaran S, et al: The role of chronic infection in children with otitis media with effusion: evidence for intracellular persistence of bacteria. Otolaryngol Head Neck Surg 2008, 138:778-781.

27. Nystrom T: Nonculturable bacteria: programmed survival forms or cells at death's door? Bioessays 2003, 25:204-211.

28. Binks MJ, Cheng AC, Smith-Vaughan H, Sloots T, Nissen M, Whiley D, et al: Viral bacterial co-infection in Australian Indigenous children with acute otitis media. BMC Infect Dis 2011, 11:161.

doi:10.1186/1472-6815-13-12

Cite this article as: Smith-Vaughan et al:: Dominance of Haemophilus influenzae in ear discharge from Indigenous Australian children with acute otitis media with tympanic membrane perforation. BMC Ear, Nose and Throat Disorders 2013 13:12.

\section{Submit your next manuscript to BioMed Central and take full advantage of:}

- Convenient online submission

- Thorough peer review

- No space constraints or color figure charges

- Immediate publication on acceptance

- Inclusion in PubMed, CAS, Scopus and Google Scholar

- Research which is freely available for redistribution 